\title{
Connexin hemichannels: novel mediators of toxicity
}

\author{
Mathieu Vinken
}

Received: 17 November 2014 / Accepted: 20 November 2014 / Published online: 28 November 2014

(C) Springer-Verlag Berlin Heidelberg 2014

Tissue homeostasis is driven by a myriad of extracellular, intracellular and intercellular signaling networks. Direct communication between neighboring cells is typically controlled by gap junctions (Decrock et al. 2009; Nielsen et al. 2012; Vinken et al. 2011). Gap junctions mediate the intercellular diffusion of small and hydrophilic substances, including cyclic adenosine monophosphate, adenosine triphosphate, inositol triphosphate, glutathione, glutamate, glucose and several ions (Alexander and Goldberg 2003) (Fig. 1a). This flux is denoted as gap junctional intercellular communication (GJIC) and is considered as a key mechanism in the maintenance of tissue functioning (Decrock et al. 2009; Nielsen et al. 2012; Vinken et al. 2011). Over the last decades, GJIC has been shown indispensable for the establishment of metabolic or electrical intercellular coupling in all vital organs, such as the brain (Eugenin et al. 2012), the heart (Kurtenbach et al. 2014) and the liver (Vinken et al. 2008). Gap junctions are formed by the docking of two hemichannels of adjacent cells, which in turn are composed of six connexin proteins. At present, 21 different connexins have been identified in humans, all which are expressed in a cell-specific way (Kar et al. 2012; Nielsen et al. 2012). They are named based upon their molecular weight. Thus, the most widespread connexin species has a molecular mass of $43 \mathrm{kDa}$ and hence is called $\mathrm{Cx} 43$. Connexin proteins share a common molecular structure consisting of four transmembrane domains, two extracellular loops, one cytosolic loop, one cytosolic aminotail and

M. Vinken ( $\square)$

Department of In Vitro Toxicology and Dermato-Cosmetology,

Vrije Universiteit Brussel, Laarbeeklaan 103, B-1090 Brussels,

Belgium

e-mail: mvinken@vub.ac.be one cytosolic carboxytail (Fig. 1b) (Decrock et al. 2009; Nielsen et al. 2012).

Although considered as merely structural precursors of gap junctions for a long time, an abundance of reports published in the last few years shows that connexin hemichannels as such can provide a pathway for cellular communication, albeit between the cytosol of individual cells and their extracellular environment and not between adjacent cells as is the case for GJIC. Nonetheless, the messengers that are conveyed through connexin hemichannels are very similar to those involved in GJIC, including adenosine triphosphate, nicotinamide dinucleotide, glutamate, glutathione, prostaglandin, sodium and calcium ions (Fig. 1a) (Chandrasekhar and Bera 2012; Decrock et al. 2009; Kar et al. 2012). Furthermore, connexin hemichannels are regulated by mechanisms that equally affect gap junctions, yet an identical factor can have opposing effects on the two channel types, such as shown for certain inflammatory triggers (De Vuyst et al. 2007; Retamal et al. 2007). In line with this notion, connexin hemichannels, unlike their full channel counterparts, display a low open probability. In fact, connexin hemichannels seem to be preferably activated by pathological stimuli, including ischemia-reperfusion insults and oxidative stress, and thereby drive processes like cell death and inflammation (Chandrasekhar and Bera 2012; Decrock et al. 2009; Kar et al. 2012). For this very reason, connexin hemichannels are sometimes considered as "pathological pores" (Decrock et al. 2009). This concept is clearly relevant to toxicologists, as several toxic substances open up connexin hemichannels. For example, ultrafine carbon black particles activate $\mathrm{Cx} 43$-based hemichannels in astrocytes, which may represent a novel mechanism of neurotoxicity (Wei et al. 2014). Similarly, cobalt-chromium nanoparticles can damage human fibroblasts by a mechanism involving transmission of adenosine 


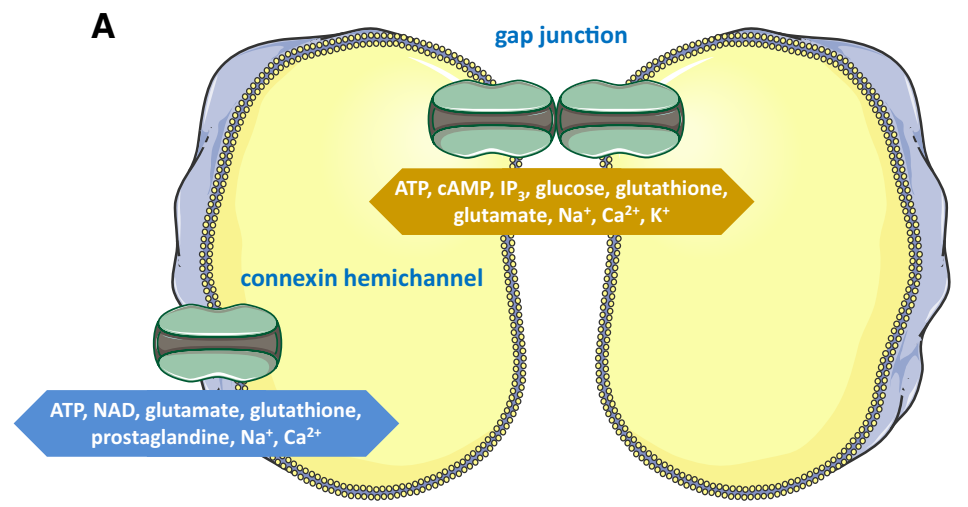

B

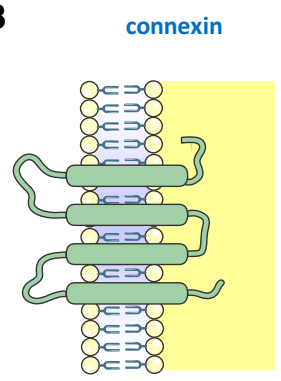

Fig. 1 a Gap junctions consist of two connexin hemichannels of adjacent cells and mediate intercellular communication. Connexin hemichannels also provide a pathway for communication, namely between the cytosol and the extracellular environment. Similar messengers travel through gap junctions and connexin hemichannels. b
Connexin proteins have four transmembrane domains, two extracellular loops, one cytosolic loop, one cytosolic aminotail and one cytosolic carboxytail (ATP adenosine triphosphate, $c A M P$ cyclic adenosine monophosphate, $I P_{3}$ inositol triphosphate, $N A D$ nicotinamide dinucleotide)

interesting experimental tools to shed light onto yet unraveled toxicological mechanisms of action, but they may also form the basis for the development of antidotes pertinent for clinical use.

\section{References}

Abudara V, Bechberger J, Freitas-Andrade M, De Bock M, Wang N, Bultynck G, Naus CC, Leybaert L, Giaume C (2014) The connexin43 mimetic peptide Gap19 inhibits hemichannels without altering gap junctional communication in astrocytes. Front Cell Neurosci 8:306

Alexander DB, Goldberg GS (2003) Transfer of biologically important molecules between cells through gap junction channels. Curr Med Chem 10:2045-2058

Bhabra G, Sood A, Fisher B, Cartwright L, Saunders M, Evans WH, Surprenant A, Lopez-Castejon G, Mann S, Davis SA, Hails LA, Ingham E, Verkade P, Lane J, Heesom K, Newson R, Case CP (2009) Nanoparticles can cause DNA damage across a cellular barrier. Nat Nanotechnol 4:876-883

Bodendiek SB, Raman G (2010) Connexin modulators and their potential targets under the magnifying glass. Curr Med Chem $17: 4191-4230$

Chandrasekhar A, Bera AK (2012) Hemichannels: permeants and their effect on development, physiology and death. Cell Biochem Funct 30:89-100

De Vuyst E, Decrock E, De Bock M, Yamasaki H, Naus CC, Evans WH, Leybaert L (2007) Connexin hemichannels and gap junction channels are differentially influenced by lipopolysaccharide and basic fibroblast growth factor. Mol Biol Cell 18:34-46

Decrock E, Vinken M, De Vuyst E, Krysko DV, D'Herde K, Vanhaecke T, Vandenabeele P, Rogiers V, Leybaert L (2009) Connexinrelated signaling in cell death: to live or let die? Cell Death Differ 16:524-536

Eugenin EA, Basilio D, Sáez JC, Orellana JA, Raine CS, Bukauskas F, Bennett MV, Berman JW (2012) The role of gap junction channels during physiologic and pathologic conditions of the human central nervous system. J Neuroimmune Pharmacol 7:499-518

Iyyathurai J, D'hondt C, Wang N, De Bock M, Himpens B, Retamal MA, Stehberg J, Leybaert L, Bultynck G (2013) Peptides and 
peptide-derived molecules targeting the intracellular domains of Cx43: gap junctions versus hemichannels. Neuropharmacology 75:491-505

Kar R, Batra N, Riquelme MA, Jiang JX (2012) Biological role of connexin intercellular channels and hemichannels. Arch Biochem Biophys 524:2-15

Kurtenbach S, Kurtenbach S, Zoidl G (2014) Gap junction modulation and its implications for heart function. Front Physiol 5:82

Nielsen MS, Axelsen LN, Sorgen PL, Verma V, Delmar M, HolsteinRathlou NH (2012) Gap junctions. Compr Physiol 2:1981-2035

Retamal MA, Froger N, Palacios-Prado N, Ezan P, Sáez PJ, Sáez JC, Giaume C (2007) Cx43 hemichannels and gap junction channels in astrocytes are regulated oppositely by proinflammatory cytokines released from activated microglia. J Neurosci 27:13781-13792

Sáez JC, Leybaert L (2014) Hunting for connexin hemichannels. FEBS Lett 588:1205-1211

Spray DC, Ye ZC, Ransom BR (2006) Functional connexin "hemichannels": a critical appraisal. Glia 54:758-773
Vinken M, Henkens T, De Rop E, Fraczek J, Vanhaecke T, Rogiers V (2008) Biology and pathobiology of gap junctional channels in hepatocytes. Hepatology 47:1077-1088

Vinken M, Decrock E, De Vuyst E, Ponsaerts R, D'hondt C, Bultynck G, Ceelen L, Vanhaecke T, Leybaert L, Rogiers V (2011) Connexins: sensors and regulators of cell cycling. Biochim Biophys Acta 1815:13-25

Wang N, De Vuyst E, Ponsaerts R, Boengler K, Palacios-Prado N, Wauman J, Lai CP, De Bock M, Decrock E, Bol M, Vinken M, Rogiers V, Tavernier J, Evans WH, Naus CC, Bukauskas FF, Sipido KR, Heusch G, Schulz R, Bultynck G, Leybaert L (2013) Selective inhibition of Cx43 hemichannels by Gap19 and its impact on myocardial ischemia/reperfusion injury. Basic Res Cardiol 108:309

Wei H, Deng F, Chen Y, Qin Y, Hao Y, Guo X (2014) Ultrafine carbon black induces glutamate and ATP release by activating connexin and pannexin hemichannels in cultured astrocytes. Toxicology $323: 32-41$ 